\title{
Malaria vectors diversity, insecticide resistance and transmission during the rainy season in peri-urban villages of south-western Burkina Faso
}

Dieudonné Diloma Soma ${ }^{1,2^{*}}$ (D), Serge Bèwadéyir Poda ${ }^{1,3}$, Aristide Sawdetuo Hien ${ }^{1,2}$, Moussa Namountougou ${ }^{1,2}$, Ibrahim Sangaré ${ }^{1,2}$, John Marie Emmanuel Sawadogo ${ }^{1 \wedge}$, Florence Fournet ${ }^{4}$, Georges Anicet Ouédraogo ${ }^{2}$, Abdoulaye Diabaté ${ }^{1}$ Nicolas Moiroux ${ }^{1,4}$ (10 and Roch Kounbobr Dabiré ${ }^{*}$

\begin{abstract}
Background: This study reports an updated description on malaria vector diversity, behaviour, insecticide resistance and malaria transmission in the Diébougou and Dano peri-urban areas, Burkina Faso.

Methods: Mosquitoes were caught monthly using CDC light traps and pyrethrum spray catches. Mosquitoes were identified using morphological taxonomic keys. PCR techniques were used to identify the species of the Anopheles gambiae complex and insecticide resistance mechanisms in a subset of Anopheles vectors. The Plasmodium sporozoite infection status and origins of blood meals of female mosquitoes were determined by ELISA methods. Larvae were collected, breed in the insectary and tested for phenotypic resistance against four insecticides using WHO bioassays.

Results: This study contributed to update the entomological data in two peri-urban areas of Southwest Burkina Faso. Anopheles populations were mostly anthropophilic and endophilic in both areas and exhibit high susceptibility to an organophosphate insecticide. This offers an alternative for the control of these pyrethroid-resistant populations. These data might help the National Malaria Control Programme for decision-making about vector control planning and resistance management.

Conclusions: This study contributed to update the entomological data in two peri-urban areas of Southwest Burkina Faso. Anopheles populations were mostly anthropophilic and endophilic in both areas and exhibit high susceptibility to an organophosphate insecticide. This offers an alternative for the control of these pyrethroid-resistant populations. These data might help the National Malaria Control Programme for decision-making about vector control planning and resistance management.
\end{abstract}

Keywords: Vector, Bionomics, Resistance, Burkina Faso

*Correspondence: dieusoma@yahoo.fr; dabireroch@gmail.com ^John Marie Emmanuel Sawadogo_-Deceased

1 Institut de Recherche en Sciences de la Santé/Centre Muraz, Bobo-Dioulasso, Burkina Faso

Full list of author information is available at the end of the article

\section{Background}

The World Health Organization (WHO) estimated to 229 million the number of cases of malaria and to 409,000 the number of death having occurred worldwide in 2019 [1]. The same year, 94\% of all malaria deaths occurred in sub-Saharan African [1] countries,

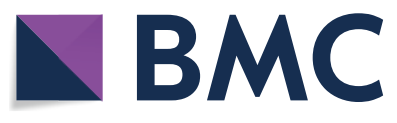

(c) The Author(s) 2021. This article is licensed under a Creative Commons Attribution 4.0 International License, which permits use, sharing, adaptation, distribution and reproduction in any medium or format, as long as you give appropriate credit to the original author(s) and the source, provide a link to the Creative Commons licence, and indicate if changes were made. The images or other third party material in this article are included in the article's Creative Commons licence, unless indicated otherwise in a credit line to the material. If material is not included in the article's Creative Commons licence and your intended use is not permitted by statutory regulation or exceeds the permitted use, you will need to obtain permission directly from the copyright holder. To view a copy of this licence, visit http://creativeco mmons.org/licenses/by/4.0/. The Creative Commons Public Domain Dedication waiver (http://creativecommons.org/publicdomain/ zero/1.0/) applies to the data made available in this article, unless otherwise stated in a credit line to the data. 
where malaria control consumes a major part of the national health budgets $[2,3]$.

The WHO's global vector control strategy recommends the scaling up of long-lasting insecticidal nets (LLINs) and indoor residual spraying (IRS) to control malaria, towards achieving the Millennium Development Goals for malaria [4, 5]. Achieving high coverage of these interventions, especially to populations at highest risk of malaria, and their continued implementation remains a major challenge [6].

In Burkina Faso, malaria is endemic with an estimated number of annual cases reaching height million, resulting in 27,800 deaths [2]. Malaria control policies in Burkina Faso include intermittent preventive treatment (IPT) for pregnant women, Seasonal Malaria Chemoprevention (SMC) for children from 0 to 5 years old and the universal coverage with LLINs, according to the WHO recommendations [7-9]. In 2011 and 2012, the National Malaria Control Programmes (NMCP) of Burkina Faso in collaboration with President's Malaria Initiative (PMI) implemented IRS as a pilot intervention in several villages of the Diébougou health district (South-West of Burkina Faso).

The implementation of insecticide-based vector control programs has led to the rapid emergence of physiological [10,11] and behavioural [12-15] resistance mechanisms in many vector populations in Africa. In Burkina Faso, recent studies indicated that Anopheles gambiae sensu lato (s.l.) was highly resistant to both pyrethroids and organochlorine [16] insecticides, but showed low levels of resistance to carbamates and organophosphates [17]. Until now, no behavioural resistance mechanism (i.e. change in biting or resting behaviour) was clearly described in Burkina Faso in relation to the implementation of vector control measures. The spread of resistance mechanisms and changes in the vector population composition may lead to a reduced efficacy of the vector control interventions [11]. It is, therefore, essential to describe and monitor malaria vector bionomics, resistance, behaviour and contribution to malaria transmission in areas where vector control measures are implemented $[18,19]$.

Therefore, in order to gather relevant data to the NMCP for decision-making about vector control planning and resistance management, we monitored vector diversity, endophagy, resistance and malaria transmission during the 2015 rainy season in two periurban areas in Southwestern Burkina Faso. Both areas received universal pyrethroid LLIN distributions in 2010 and 2013 and one of both received bendiocarb IRS in 2011 and 2012 as part of a PMI pilot intervention.

\section{Methods}

\section{Study areas}

The survey was carried out during the 2015 rainy season in the-29 $\mathrm{km}$ apart-peri-urban areas of Diébougou (N10.96741; W 003.24580) and Dano (N11.14288; W 003.05969) cities, in South-West Burkina Faso (Fig. 1). Both areas have similar environmental characteristics with an average $1000 \mathrm{~mm}$ annual rainfall occurring from May to October and a vegetation dominated by wooded savannah. Surveys were performed in height sites named Diébougou centre, Bagane, Loto and Bapla in the Diébougou area; and sector one to four in Dano. The main economic activity is agriculture in both areas where animals and humans use to live very closely in the same courtyard. In the Diébougou area, bendiocarb IRS was implemented in 2011 and 2012. Populations of both areas received free of charge LLINs in 2010 and 2013 in the framework of the NMCP national mass distribution.

\section{Study design and mosquito collections}

Monthly mosquito collections were carried out from August to November 2015. One inhabited house was randomly selected in each site (i.e. 4 houses per study area). These houses were made of mud or cement with traditional roof or metal sheeting and were representative of the local housing. Mosquito collections were performed using CDC light trap both indoor and outdoor of each selected house during four successive nights from 18:00 to 06:00. Thus, 32 trap-night collections were performed per month and per area. Each month, early morning mosquito collections were also performed using pyrethrum spraying catches (PSC) inside 10 randomly selected inhabited houses over 4 consecutive days in each site (for a total of 40 houses per area per month).

\section{Laboratory processing of adult Anopheles (from CDC traps and pyrethrum spraying catches collections)}

All collected Anopheles adults were morphologically identified under a stereomicroscope to the species complex and preserved in $1.5 \mathrm{ml}$ tubes containing silicagel [20]. Unfed females form CDC light traps belonging to the An. gambiae complex were dissected to determined their physiological age using the Detinova method [21]. A randomly selected sub-sample (25 female per house per month) of females collected in light traps and belonging to the An. gambiae complex were proceed by Polymerase Chain Reaction (PCR) for species identification following the protocol described by Santolamazza et al. [22]. Female infection by Plasmodium falciparum was also 


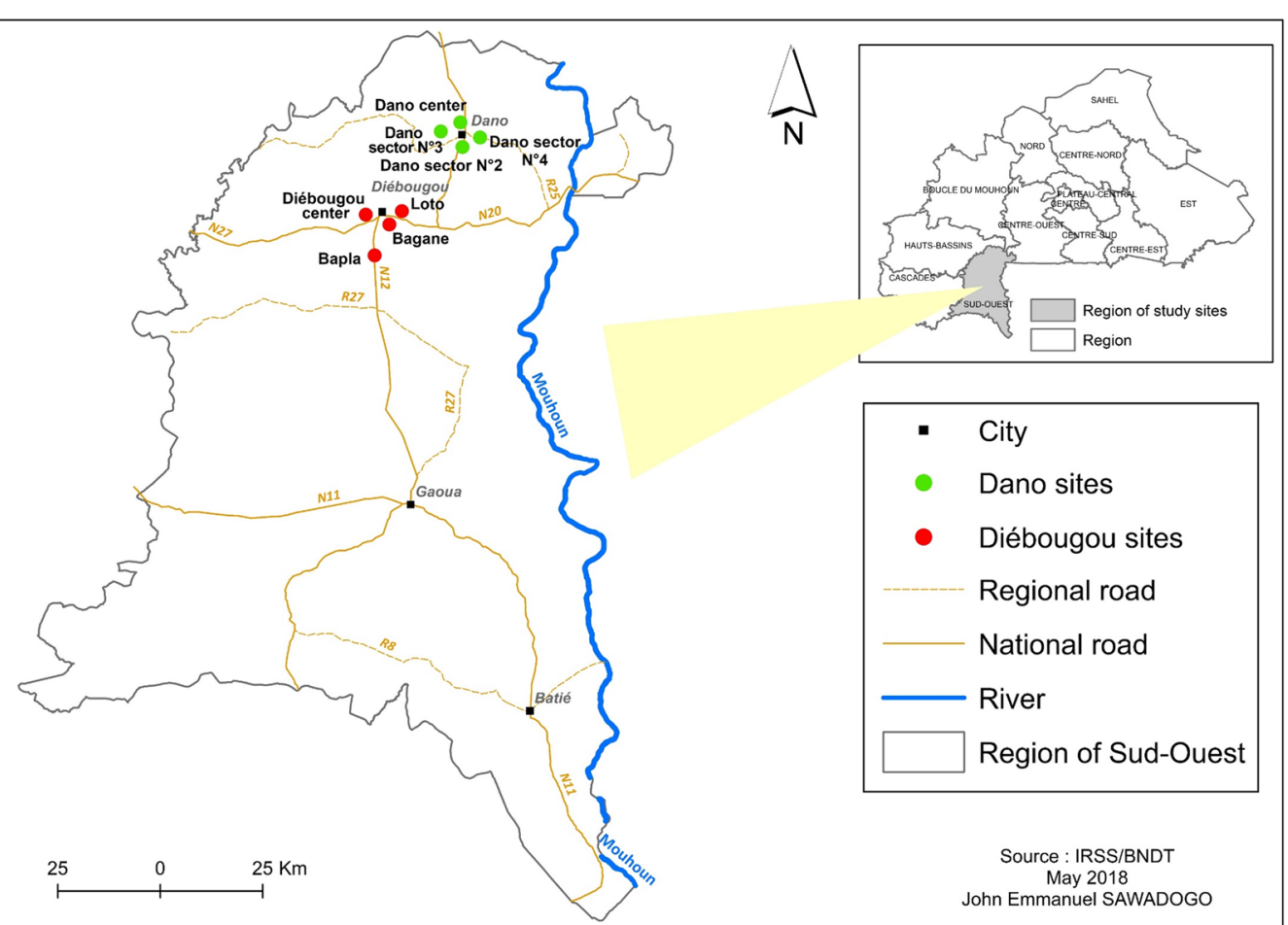

Fig. 1 Location of the study areas and mosquito collection sites

assessed on the same subsample using enzyme-linked immunosorbent assays (ELISA) technique described by Wirtz et al. [23]. Abdomen of blood-fed females collected indoor by PSC were analysed for identification of blood meal source by the ELISA technique [24].

\section{Bioassay}

Anopheles larvae were collected from natural breeding sites throughout the two peri-urban areas of Diébougou and Dano. In each study area, mosquito larvae were collected in at least 10 breeding sites distant from each other by at least $200 \mathrm{~m}$. Larvae were then pooled together, brought back to the IRSS insectarium and reared under controlled conditions (temperature $27 \pm 2{ }^{\circ} \mathrm{C}$, Relative humidity $70 \pm 10 \%$ ) until adult's emergence. Non-bloodfed 3-5 days-old females morphologically identified as An. gambiae s.l. were put in contact with DDT 4\%, deltamethrin $0.05 \%$, bendiocarb $0.1 \%$ and chlorpyriphos methyl $0.1 \%$ impregnated filter papers following the WHO standard protocol [25]. Four replicates of 20-25 individuals were exposed to each tested insecticide. Anopheles gambiae "Kisumu" strain was used as the susceptible control strain [25]. Mortality was recorded 24 hours after exposure. PCR analyses were then conducted on a subsample of 200 females per area to detect the $k d r$ (L1014F) and ace-1 (G119S) mutations using the protocol described by Martinez-Torres et al. [26] and Weill et al. [27], respectively.

\section{Entomological indicators and statistical analysis}

Mosquito density per trap per night was calculated for each malaria vector species as the number of Anopheles individuals collected per trap per night. Endophagy rate (ER) was the proportion of mosquito collected indoors from CDC light traps. Parous rate (PR) was calculated as the proportion of parous An. gambiae s.l. among dissected individuals. The Plasmodium-sporozoite rate (SR) of infection was calculated as the proportion of mosquitoes positive for CSP-ELISA. Human Blood Index (HBI) was the proportion of mosquitoes found to be fed on Humans relative to the total number tested.

All other statistical analyses were performed using the software $\mathrm{R}$ version 3.6.0 [28]. A generalized linear mixed model (GLMM) fitting a negative binomial distribution of the error was applied to compare Anopheles densities between areas and species. The collection site, position (indoor or outdoor) and date were included in the model as random intercepts (sites and positions were nested). 
Table 1 Anopheles densities in the study areas collected in 2015

\begin{tabular}{|c|c|c|c|c|c|c|c|c|}
\hline \multirow[t]{2}{*}{ Districts } & \multirow[t]{2}{*}{ Sampling method } & \multicolumn{2}{|c|}{ An. gambiae s.l. } & \multicolumn{2}{|c|}{ An. funestus group } & \multicolumn{2}{|c|}{ An. nili } & \multirow[t]{2}{*}{ Total } \\
\hline & & $\mathbf{n}$ & $\%$ & $\mathbf{n}$ & $\%$ & $\mathbf{n}$ & $\%$ & \\
\hline \multirow[t]{2}{*}{ Diébougou } & CDC & 1862 & 73.30 & 664 & 26.14 & 14 & 0.55 & 2540 \\
\hline & PSC & 1394 & 88.00 & 190 & 11.99 & 0 & 0.00 & 1584 \\
\hline \multirow[t]{2}{*}{ Dano } & CDC & 3202 & 92.38 & 254 & 7.32 & 10 & 0.28 & 3466 \\
\hline & PSC & 1962 & 96.41 & 73 & 3.58 & 0 & 0.00 & 2035 \\
\hline
\end{tabular}

PSC pyrethrum spray catches, $C D C C D C$ light traps, $n$ number of mosquitoes

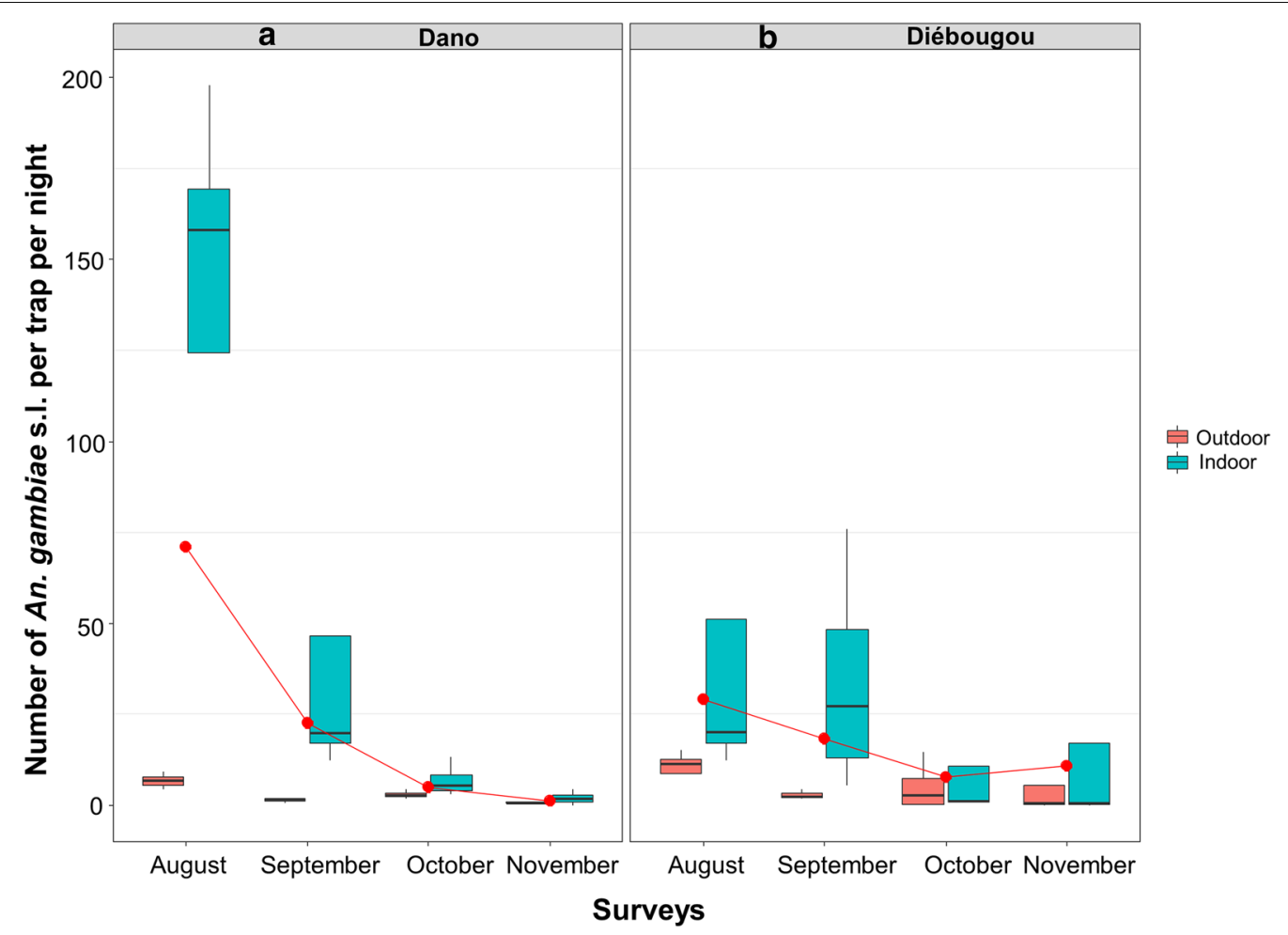

Fig. 2 Mean nightly densities of An. gambiae s.l. collected using light-traps. Boxes indicate inter-quartile range (IQR) and median of number of An. gambiae s.l per trap. The upper whisker extends to the largest value no further than $1.5^{*}$ IQR from the hinge. Red dots show the mean nightly densities per month

The human blood index of both An. gambiae s.l. and Anopheles funestus were compared between areas using logistic regression. The SR, PR, and ER were compared between areas using binomial GLMMs fitted on individual data and for both An. gambiae s.l. and An. funestus. The collection site and date were included in the model as random intercepts. GLMM were fitted using the glmmTMB function of the glmmTMB package [29]. The post-hoc Tukey's method was used to perform multiple comparison among modalities of the fixed terms. The 'emmeans' function of the 'emmeans' package [30] was used to compute Density rate ratios (DRR) and Odds ratios (OR) with 95\% confidence intervals for Negative Binomial and Binomial models, respectively. The allelic frequencies of the $k d r$ and ace-1 mutations in An. gambiae s.l. populations were calculated and compared using the 'GenePop' package in R [31].

\section{Results}

Malaria vector morphological identification, densities and behaviour

A total of 9625 Anopheles mosquitoes was collected (6006 by CDC traps and 3619 by PSC) (Table 1). Anopheles gambiae s.l. was the most abundant species in both 


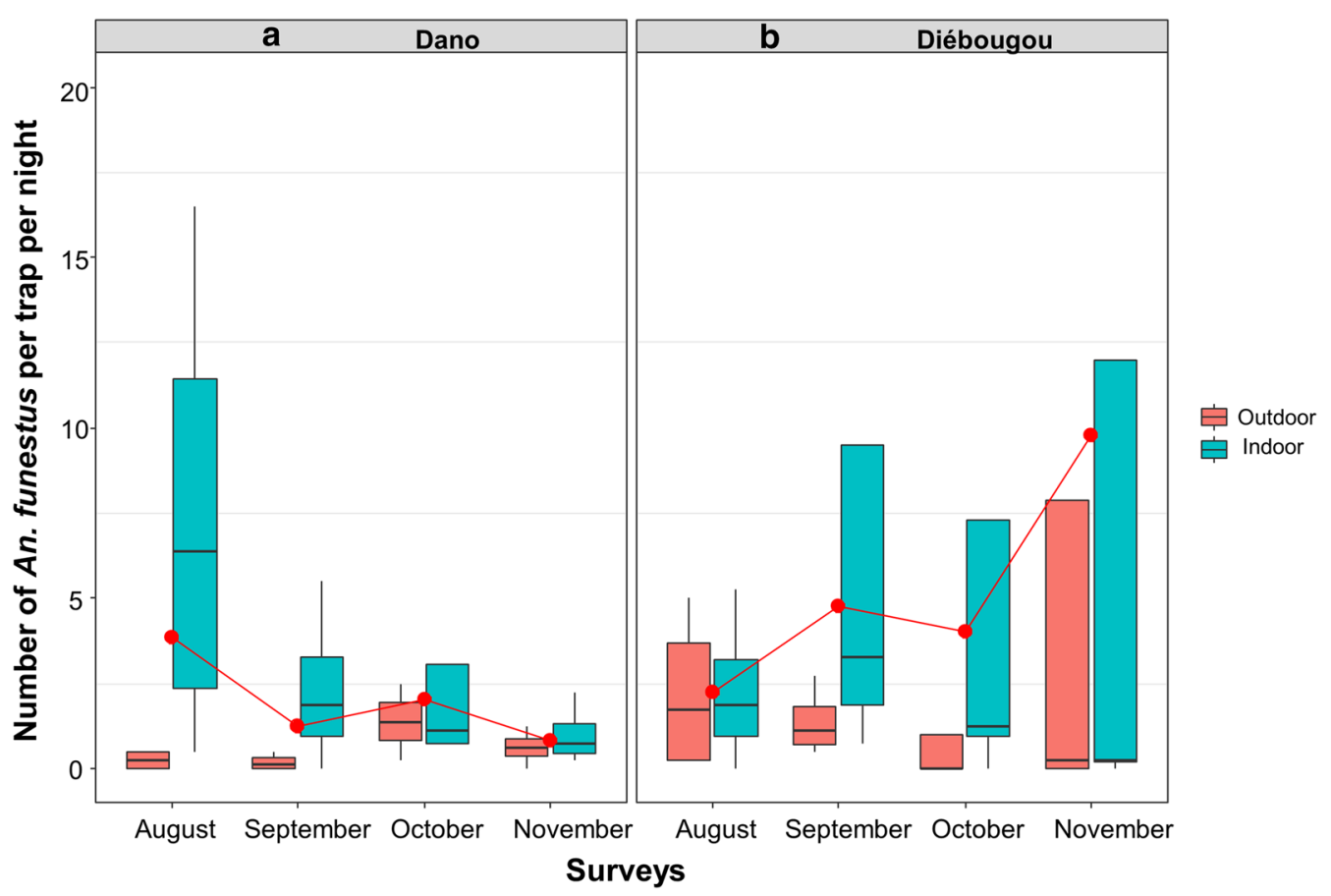

Fig. 3 Mean nightly densities of An. funestus group collected using light-traps. Boxes indicate inter-quartile range (IQR) and median of number of An. funestus group per trap. The upper whisker extends to the largest value no further than 1.5* IQR from the hinge. Red dots show the mean nightly densities per month

areas whatever the collection method $(84.3 \%$ by CDC traps and $92.7 \%$ by PSC), followed by An. funestus group (13.2\% by CDC traps and $6.7 \%$ by PSC) (Table 1$)$. Only 24 (0.4\%) Anopheles nili individuals were caught, all by CDC traps (Table 1).

Regarding mosquitoes collected by CDC light trap, the mean density of Anopheles per trap and per night was 21.9 in Diébougou not significantly different than 27.1 in Dano (Density Rate Ratio DRR $=1.10$, IC95\% [0.23; 5.17]; $\mathrm{P}=0.89$ ). The mean density of An. gambiae s.l. per trap and per night was 25.0 in Dano, higher than 16.6 in Diébougou (DRR $=1.25$, IC95\% $[0.27 ; 5.83] ; \mathrm{P}=0.77)$. Densities were at their maximum during August in both area (71.1 and 29.1 in Dano and Diébougou, respectively) and decreased the following months (Fig. 2a, b). The mean density of An. funestus group per trap per night was 5.1 in Diébougou, higher than 1.9 in Dano (DRR $=0.80$, IC95\% [0.17; 3.79]; P=0.77). In Dano, An. funestus densities decreased from 3.8 to 0.8 between August and November while during the same period in Diébougou, they increased from 2.2 to 9.7 (Fig. 3a, b).

The mean density of Anopheles per house collected by PSC was 2.90 in Dano and 2.47 in Diébougou (Density Rate Ratio DRR $=0.92$, IC95\% [0.37; 2.25]; $\mathrm{P}=0.85$ ). Indoor resting densities of An. gambiae s.l. were the highest in August in Dano (7.0) than in September in Diébougou (4.8; Fig. 4a, b). Indoor resting densities of An. funestus group were the highest in November in both areas (0.17 and 0.73 in Dano and Diébougou respectively, Fig. 5a, b).

Mean Endophagy rate (ER) of An. gambiae s.l. as estimated by the GLMM was $89.1 \%$ [95\%CI] [67.2; 97.0] in Dano significantly higher than $70.0 \% \%[36.9 ; 90.3]$ in Diébougou (OR [95\% CI] 3.50 [1.08; 11.3], P=0.03). Mean Endophagy rate (ER) of An. funestus group was 83.8\% [67.8; 92.7] in Dano not significantly different than $67.8 \%$ [45.5; 84.2] in Diébougou (OR [95\% CI] 2.46 $[0.90,6.69], \mathrm{P}=0.07)$.

\section{Molecular identification of Anopheles gambiae}

Over the $400 \mathrm{An}$. gambiae s.l. individuals selected per area for molecular identification, $84.50 \%(338 / 400)$ from Diébougou and 95.50\% (382/400) from Dano were successfully identified. Anopheles gambiae sensu stricto (s.s.) was the most represented species belonging to the An. gambiae complex in both study areas (70.5\%, $\mathrm{n}=338$ in Diébougou and 68.2\%, $\mathrm{n}=382$ in Dano) followed by Anopheles coluzzii (22.1\%, $\mathrm{n}=106$ in Diébougou and 23.5\%, $\mathrm{n}=132$ in Dano) (Table 2) and 


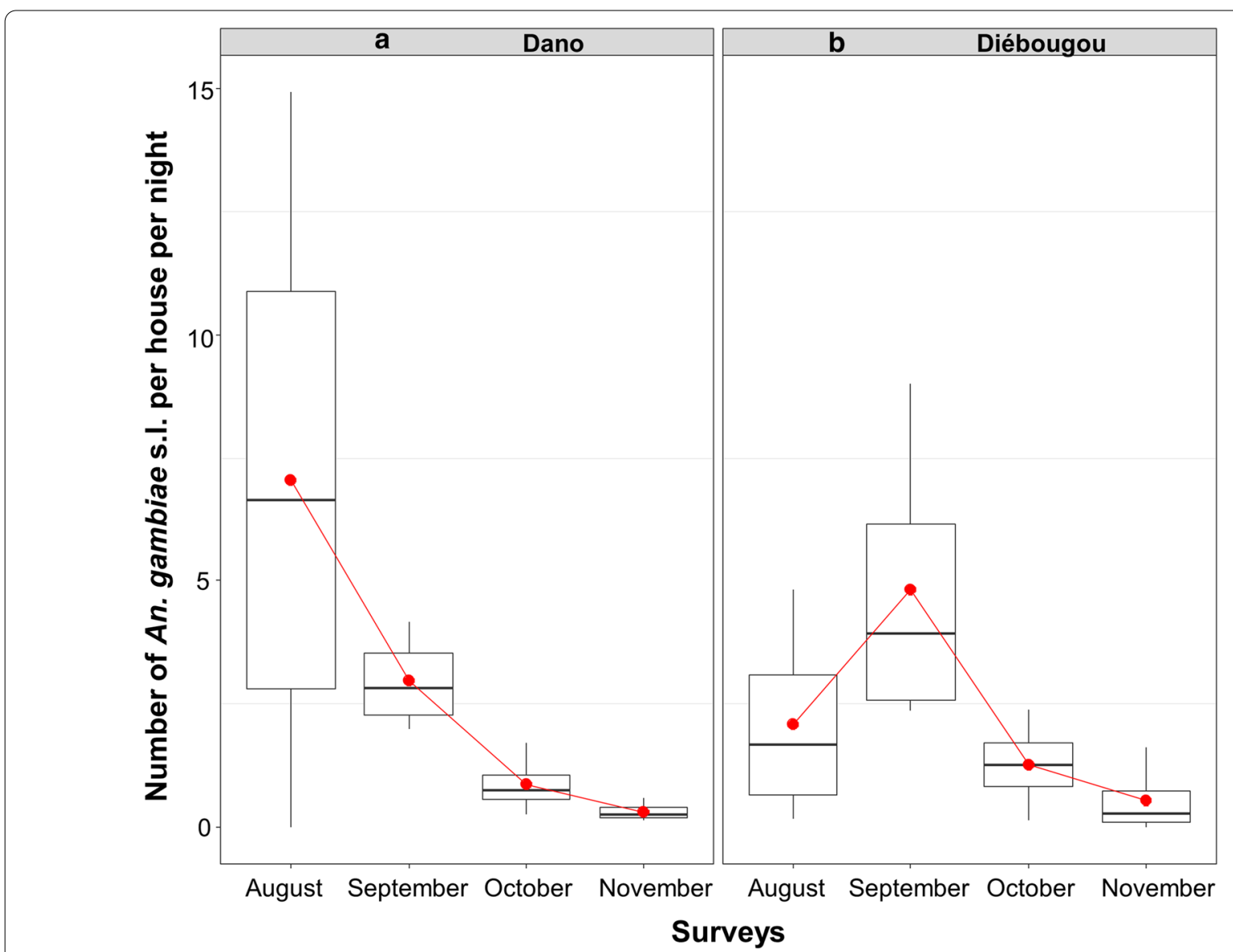

Fig. 4 Mean indoor resting densities of An. gambiae s.I. Boxes indicate inter-quartile range (IQR) and median of number of An. gambiae s.l. per house. The upper whisker extends from the hinge to the largest value no further than $1.5^{*}$ IQR from the hinge. Red dots show the mean indoor resting densities per month

Anopheles arabiensis $(7.3 \%, \mathrm{n}=35$ in Diébougou and $8.2 \%, \mathrm{n}=46$ in Dano).

\section{Plasmodium infection}

The mean sporozoite rate [IC95\%] of An. gambiae s.l. as estimated by the GLMM was 7.7\% [2.7-19.9] in Dano and 13.2 [5.1-30.6] \% in Diébougou. The SR of $A n$. gambiae s.l. did not differ significantly between areas $(\mathrm{OR}=0.55$; IC95\% [0.17; 1.72]; $\mathrm{P}=0.29)$.

An. funestus group sporozoite rate was estimated to be $4.6 \%$ [2.1-9.6] in Dano and 1.4\% [0.01-3.1] \% in Diébougou. The mean SR of An. funestus group in Dano was significantly higher than that in Diébougou $(\mathrm{OR}=3.29$; IC95\% [1.09; 9.96]; $\mathrm{P}=0.03)$.

\section{Parous rate and blood-feeding preference in Anopheles gambiae s.l.}

The mean parous rate [IC95\%] as estimated by the GLMM was 66.25\% [60.96-71.17] in Dano, not significantly different than in Diébougou (64.44\% [58.56-69.91]; $\mathrm{OR}=1.25 ;[0.88,1.79] ; \mathrm{P}=0.21)$. A total of 1552 bloodfed Anopheles (626 from Dano and 926 form Diébougou) were tested for blood feeding preference (human, cattle, donkey, pig) (Table 3). Overall, the proportion of An. gambiae s.l. that fed on human was $68.1 \%(408 / 599)$ in Dano and 68.8\% (516/749) in Diébougou. The overall human blood index did not differ significantly between Dano and Diébougou (OR $=0.81$; IC95\% [0.47; 1.38]; $\mathrm{P}=0.22$ ). The proportion of An. funestus group females that fed only on human was $51.8 \%(14 / 27)$ in Dano, not 


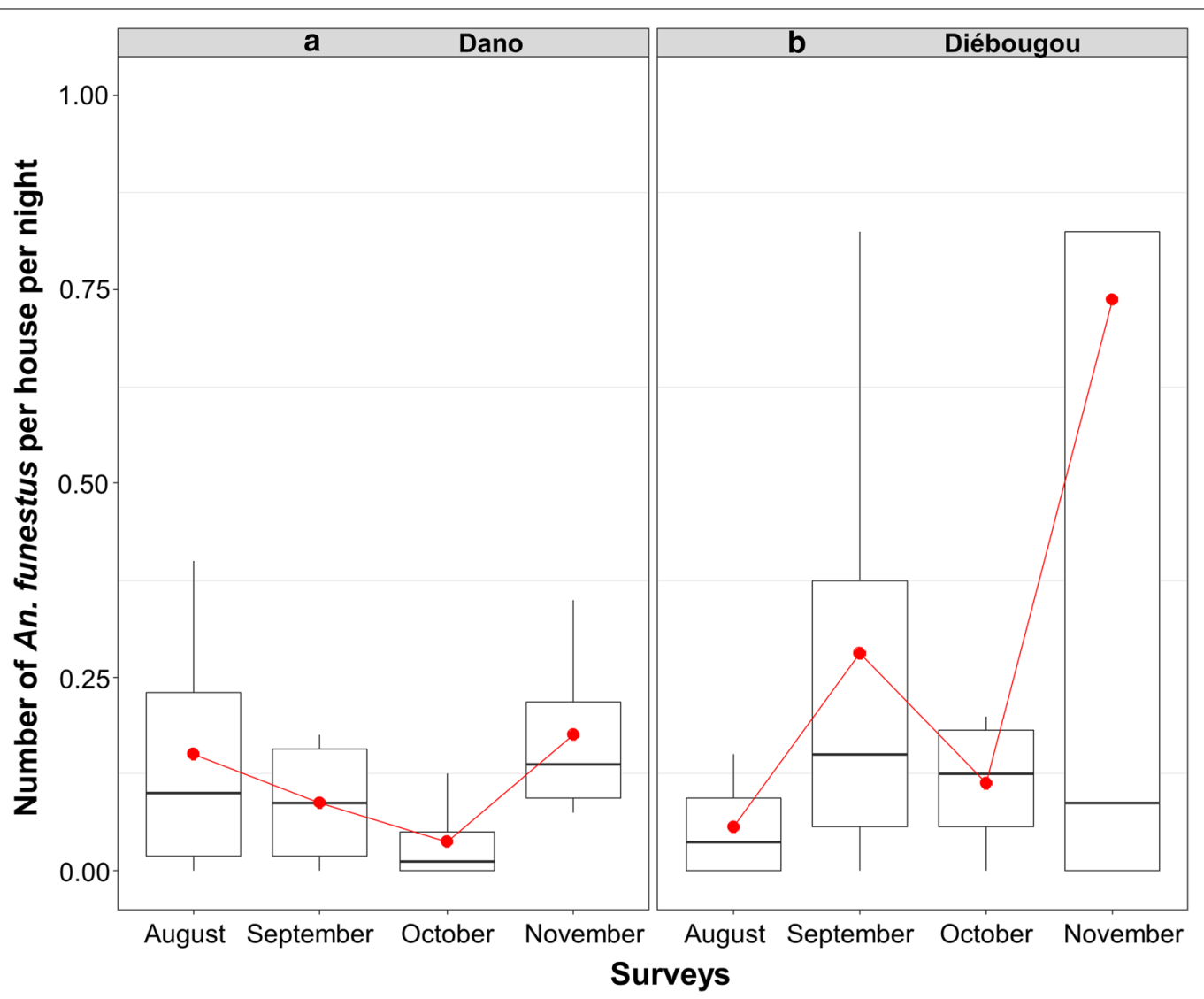

Fig. 5 Mean indoor resting densities of An. funestus group. Boxes indicate inter-quartile range (IQR) and median of number of An. funestus group per house. The upper whisker extends from the hinge to the largest value no further than $1.5^{*}$ IQR from the hinge. Red dots show the mean indoor resting densities per month

Table 2 Species composition of Anopheles gambiae complex 2015

\begin{tabular}{|c|c|c|c|c|c|c|c|}
\hline \multirow[t]{2}{*}{ Districts } & \multirow[t]{2}{*}{ An. gambiae s.l. } & \multicolumn{2}{|c|}{ An. gambiae s.s. } & \multicolumn{2}{|c|}{ An. coluzzii } & \multicolumn{2}{|c|}{ An. arabiensis } \\
\hline & & $\mathrm{n}$ & $\%$ & $\mathrm{n}$ & $\%$ & $n$ & $\%$ \\
\hline Diébougou & 479 & 338 & 70.5 & 106 & 22.1 & 35 & 7.3 \\
\hline Dano & 560 & 382 & 68.2 & 132 & 23.5 & 46 & 8.2 \\
\hline
\end{tabular}

$n$ number of mosquitoes

significantly different than 61.0\% (108/177) in Diébougou $(\mathrm{OR}=0.65$; IC95\% [0.11, 3.77]; $\mathrm{P}=0.4)$.

\section{Anopheles gambiae susceptibility to insecticides}

Mortality rates of Anopheles gambiae s.l. from both areas were $100 \%$ with chlorpyrifos methyl $0.4 \%$ (Fig. 6) indicating full susceptibility to this insecticide. With benthiocarb $0.1 \%$, mortality rates were $71.1 \%$ and $62.0 \%$ in Diébougou and Dano, respectively, indicating resistance. With deltamethrin $0.05 \%$, mortality rates were $32 \%$ and $27.33 \%$ in Diébougou and Dano, respectively. When exposed to DDT $4 \%$, mortality rates were only $14 \%$ and 13.6\% in Diébougou and Dano, respectively (Fig. 6). 
Table 3 Blood meal source of An. gambiae s.l. and An. funestus group from Diébougou and Dano areas in 2015

\begin{tabular}{|c|c|c|c|c|c|c|c|c|c|c|}
\hline \multirow[t]{2}{*}{ Sites/species } & \multicolumn{5}{|c|}{ Animals } & \multicolumn{2}{|c|}{ Human } & \multicolumn{2}{|c|}{ Mixed } & \multirow{2}{*}{$\begin{array}{l}\text { Total } \\
\text { n }\end{array}$} \\
\hline & Cattle & Donkey & Pig & Other & $\%$ & $\mathrm{n}$ & $\%$ & $\mathbf{n}$ & $\%$ & \\
\hline \multicolumn{11}{|l|}{ Diébougou } \\
\hline An. gambiaes.l. & 35 & 2 & 1 & 176 & 28.5 & 516 & 68.8 & 19 & 2.5 & 749 \\
\hline An. funestus group & 3 & 0 & 1 & 51 & 31.0 & 108 & 61.0 & 14 & 7.9 & 177 \\
\hline Total & 38 & 2 & 2 & 227 & 29.0 & 624 & 67.3 & 33 & 3.5 & 926 \\
\hline \multicolumn{11}{|l|}{ Dano } \\
\hline An. gambiaes.l. & 4 & 1 & 1 & 127 & 22.2 & 408 & 68.1 & 58 & 9.6 & 599 \\
\hline An. funestus group & 1 & 0 & 0 & 9 & 37.0 & 14 & 51.8 & 3 & 11.1 & 27 \\
\hline Total & 5 & 1 & 1 & 136 & 22.8 & 422 & 67.4 & 61 & 9.7 & 626 \\
\hline
\end{tabular}

$n$ number of blood-fed Anopheles females, Other other animals not determined, Mixed fed on both animal and human

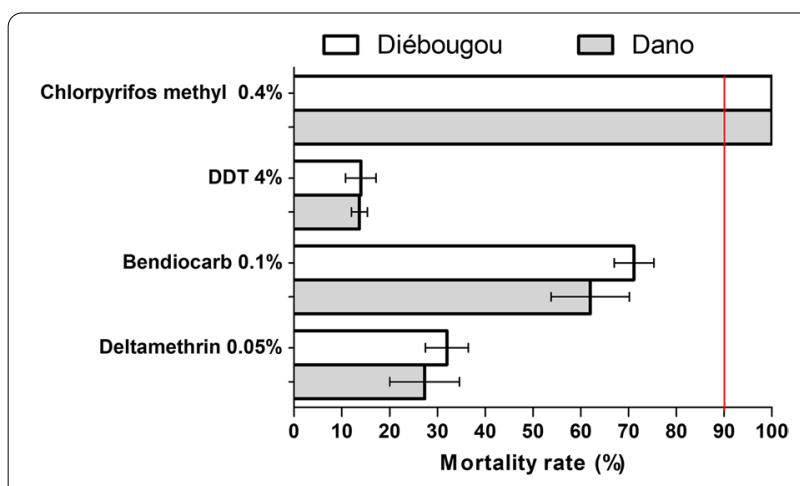

Fig. 6 Mortality rates recorded in WHO cone test of wild populations of An. gambiae s.l. originated from Diébougou and Dano exposed to four insecticides. Red vertical line indicates the resistance threshold according to the WHO. 95\% confidence intervals are shown

\section{Allele frequencies of the $k d r$ and ace- 1 mutations}

The frequencies of the $k d r$ mutation were high in both An. coluzzii (0.93 and 0.74 in Diébougou and Dano, respectively) and An. gambiae sensu stricto (s.s.) (0.84 and 0.85 in Diébougou and Dano, respectively) (Table 4).
For Anopheles arabiensis, this mutation was detected only in individuals from Diébougou and at a moderate frequency (0.342) (Table 4). Frequencies of $k d r$ mutation differ significantly between areas (Diébougou and Dano) in An. arabiensis (exact $\mathrm{G}$ test $\mathrm{P}<0.0001$ and $A n$. coluzzii (exact $\mathrm{G}$ test $\mathrm{P}<0.001$ ) but not in $A n$. gambiae s.s. (exact $\mathrm{G}$ test $\mathrm{P}=0.53$ ).

The results showed very low frequencies of the ace1 mutation in all areas and species $(0.037$ and 0.046 for An. coluzzii in Diébougou and Dano, respectively; 0.032 and 0.024 for An. gambiae s.s. in Diébougou and Dano, respectively; Table 4). These frequencies did not vary between areas (An. coluzzii : exact $\mathrm{G}$ test $\mathrm{P}=0.79 ; A n$. gambiae s.s.: exact $\mathrm{G}$ test $\mathrm{P}=0.55)$. We failed to detect any homozygous resistant (RR) individual for this mutation (Table 4).

\section{Discussion}

The entomological monitoring that we carried out revealed that $A n$. gambiae s.l. and An. funestus group were the main malaria vectors in both Diébougou and

Table 4 Allelic and genotypic frequencies at the kdr-west and ace-1 locus in An. gambiae s.l. populations from Diébougou and Dano areas

\begin{tabular}{|c|c|c|c|c|c|c|c|c|c|c|}
\hline \multirow[t]{3}{*}{ Species } & \multirow[t]{3}{*}{ Sites } & \multirow[t]{3}{*}{$\mathbf{n}$} & \multicolumn{3}{|c|}{ Genotypes $k d r$} & \multirow[t]{3}{*}{$f(L 1014 F)$} & \multicolumn{3}{|c|}{ Genotypes ace 1} & \multirow[t]{3}{*}{$f(119 S)$} \\
\hline & & & 1014L & 1014L & $1014 \mathrm{~F}$ & & $119 \mathrm{G}$ & $119 \mathrm{G}$ & $119 S$ & \\
\hline & & & 1014L & $1014 \mathrm{~F}$ & $1014 \mathrm{~F}$ & & $119 \mathrm{G}$ & $119 S$ & $119 S$ & \\
\hline \multirow[t]{2}{*}{ An. arabiensis } & Diébougou & 19 & 12 & 1 & 6 & 0.342 & 19 & 0 & 0 & 0.000 \\
\hline & Dano & 21 & 21 & 0 & 0 & 0.000 & 21 & 0 & 0 & 0.000 \\
\hline \multirow[t]{2}{*}{ An. coluzzii } & Diébougou & 94 & 6 & 0 & 88 & 0.936 & 87 & 7 & 0 & 0.037 \\
\hline & Dano & 98 & 12 & 27 & 59 & 0.740 & 89 & 9 & 0 & 0.046 \\
\hline \multirow[t]{2}{*}{ An. gambiae s.s } & Diébougou & 238 & 36 & 3 & 199 & 0.842 & 223 & 15 & 0 & 0.032 \\
\hline & Dano & 231 & 21 & 23 & 187 & 0.859 & 220 & 11 & 0 & 0.024 \\
\hline
\end{tabular}

$N$ number of mosquitoes, $f(1014 \mathrm{~F})$ frequency of the $1014 \mathrm{~F}$ resistant $k d r$ allele, $f(119 S)$ frequency of the $119 \mathrm{~S}$ resistant ace- 1 allele 
Dano areas. The density of An. gambiae s.l. (major vector) fell down drastically in October and November, compared to the two previous months. This was also true for An. funestus in Dano. However, in Diébougou, we collected more An. funestus individuals in October and November (especially in November). The predominance of An. gambiae s.l. could be explained by the presence of its preferential deposits, consisting in temporary shallow and sunny water collections associated with rainfall $[32,33]$. The increased densities of An. funestus group at the end of the rainy seasons in Diébougou might be explained by the presence, in the Bapla site, of a dam that provides permanent and semipermanent breeding sites typically associated with the presence of this species [33-36]. Similar observations have been reported by Dabiré et al. [37] in two savannah villages (Soumousso and Lena) in Burkina Faso, where An. funestus group was found as the major malaria vector towards the end of the rainy season.

Mean parous and sporozoite infection rates of $A n$. gambiae s.l. were high, indicating that older females were more prevalent and probably capable of malaria transmission during the rainy season in both study sites. These results corroborate previous studies carried out in the savannah areas of Bobo-Dioulasso, Burkina Faso [38] and Gansé, Côte d'Ivoire [39]. These data highlight the need for the correct use of protective tools such as LLINs. This situation could contribute to reduce human-vector contact and induce a decrease in the human population that is not very infectious for the vectors as well as mortality in the epidemiologically dangerous stages (parous female) [40, 41].

Despite many years of continuous implementation of indoor, insecticide-based, vector control measures (LLINs alone or in combination with carbamate-IRS) in the study areas, Anopheles populations continue to exhibits mainly anthropophilic and endophilic behaviours, similarly to prior descriptions in closed area [37]. This seems to indicate, at the opposite to what was found in other areas [12, 18, 19], that LLINs and IRS did not induced significant change in vectors behaviour in Dano and Diébougou. This situation may be explained by the high pyrethroid-resistance levels $[42,43]$ observed in the vector population well before the 2010 and 2013 LLINs distributions.

In both areas of this study, An. gambiae populations were resistant to bendiobarb, DDT and pyrethroid. The intensive use of these insecticides in agriculture (gardening, rice and cotton growing) as well as in public health (IRS, LLINs) was found to induce selection of insecticide resistance in malaria vectors [44]. Cotton is intensively cultivated around Dano and Diébougou and was shown to possibly induce strong selection pressure malaria vectors [45]. This constitutes a limit to the efficacy of vector control strategies based on pyrethroids (such as LLINs) and carbamates in this part of the country. However, susceptibility tests indicated that An. gambiae was still susceptible to chlorpyriphos-methyl, an organophosphate that received a recommendation for its use in IRS [46]. This insecticide family might therefore be used in this area of Burkina Faso in combination with pyrethroids-LLIN with the goal to manage pyrethroids resistance and help reduce malaria transmission $[47,48]$.

In this study, we characterize phenotypic resistance of An. gambiae s.l. and identify the $k d r$ mutation as a probable major cause for pyrethroids and DDT resistance. However, we did not investigated the role of metabolic resistance (such as esterase, oxidase and glutathione$S$-transferase) that might have contributed to pyrethroids resistance and explained carbamate resistance $[49,50]$. Moreover, insecticide resistance in An. funestus was not investigated. Because this species is a major malaria vector in the area, particularly at the end of the rainy season, further studies should consider describing phenotypic resistance and the mechanisms involved.

\section{Conclusions}

This study contributed to update the entomological data in two peri-urban areas of Southwest Burkina Faso. Anopheles populations (An. gambiae s.l. and An. funestus group) were mostly anthropophilic and endophilic in both areas. Furthermore, the high susceptibility of vector populations to organophosphates offers an alternative for the control of these pyrethroid-resistant populations. These data might help NMCP for decision-making about vector control planning and resistance management. However, it is necessary to characterize insecticide resistance in the An. funestus population in order to get the whole picture.

\section{Abbreviations}

WHO: World Health Organization; CDC: Center Disease Control; LLINs: Longlasting insecticidal nets; IRS: Indoor residual spraying; IPT: Intermittent preventive treatment; SMC: Seasonal malaria chemoprevention; NMCP: National Malaria Control Programmes; PMI: U.S. President's Malaria Initiative; PSC: pyrethrum spraying catches; PCR: Polymerase chain reaction; ELISA: Enzymelinked immunosorbent assays.

\section{Acknowledgements}

The authors are grateful to the technicians at IRSS/Centre Muraz for their key work especially Mr Ouari Ali and Mr Méda Georges Benson. We also thank the District Medical team and local authorities for their participation in the study. Our sincere appreciation to the communities from all selected sentinel sites for the support and cooperation during experiments.

\section{Authors' contributions}

RKD designed the study. MN, IS, SBP and DDS contributed to the implementation of the study. SBP, MN and DDS performed laboratory and fieldwork. JEMS realized the maps. NM and DDS analysed the data. NM and DDS interpreted 
the results and drafted the manuscript, which was critically revised by coauthors. All authors read and approved the final manuscript.

\section{Funding}

This study was supported by Jhpiego/ABT/PMI project N 15_TSC_115.

\section{Availability of data and materials}

The datasets used during the current study are available from the corresponding author on reasonable request.

\section{Ethics approval and consent to participate}

Entomological surveys did not involve human or animal volunteers. However, we acquired informed consents in writing (or with a fingerprint if illiterate) from head of households to use their houses for mosquitoes collection.

\section{Consent for publication}

Not applicable.

\section{Competing interests}

The authors declare that they have no competing interests.

\section{Author details}

${ }^{1}$ Institut de Recherche en Sciences de la Santé/Centre Muraz, Bobo-Dioulasso, Burkina Faso. ${ }^{2}$ Université Nazi Boni, Bobo-Dioulasso, Burkina Faso. ${ }^{3}$ Université Joseph Ki-Zerbo, Ouagadougou, Burkina Faso. ${ }^{4}$ MIVEGEC, Univ. Montpellier, CNRS, IRD, Montpellier, France.

Received: 2 April 2020 Revised: 14 December 2020 Accepted: 16 December 2020

Published online: 25 January 2021

\section{References}

1. WHO. World Malaria Report 2020. Geneva WH, Organization; 2020. http:// www.who.int/malaria/publications/world-malaria-report-2020

2. WHO. World malaria report 2019. Geneva. Organization WH; 2019. http:// www.who.int/malaria/publications/world-malaria-report-2019.

3. WHO. World malaria report 2018. Geneva. Organization WH; 2018. http:// www.who.int/malaria/publications/world-malaria-report-2018.

4. WHO. World malaria report 2017. Geneva. Organization WH; 2017. http:// www.who.int/malaria/publications/world-malaria-report-2017.

5. Hemingway J, Shretta R, Wells TNC, Bell D, Djimdé AA, Achee N, et al. Tools and strategies for malaria control and elimination: what do we need to achieve a grand convergence in malaria? PLoS Biol. 2016;14:e1002380.

6. OMS. Stratégie technique mondiale de lutte contre le paludisme 2016-2030. Geneva: World Health Organization; 2016.

7. PNLP. Directives nationales pour la prise en charge du paludisme dans les formations sanitaires du Burkina Faso. Ministère la Santé/Burkina Faso; 2014.

8. Ministère de la Santé. Annuaire statistique (2017). Ouagadougou: Ministère de la Santé; 2017.

9. Ministère de la Santé. Annuaire statistique/Santé 2005. Ouagadougou: Ministère de la Santé; 2006.

10. Ranson H, N'guessan R, Lines J, Moiroux N, Nkuni Z, Corbel V. Pyrethroid resistance in African anopheline mosquitoes: what are the implications for malaria control? Trends Parasitol. 2011;27:91-8.

11. Ranson $\mathrm{H}$, Lissenden $\mathrm{N}$. Insecticide resistance in African Anopheles mosquitoes: a worsening situation that needs urgent action to maintain malaria control. Trends Parasitol. 2016;32:187-96.

12. Moiroux N, Gomez MB, Pennetier C, Elanga E, Djènontin A, Chandre F, et al. Changes in Anopheles funestus biting behavior following universal coverage of long-lasting insecticidal nets in Benin. J Infect Dis. 2012;206:1622-9.

13. Russell TL, Govella NJ, Azizi S, Drakeley CJ, Kachur SP, Killeen GF. Increased proportions of outdoor feeding among residual malaria vector populations following increased use of insecticide-treated nets in rural Tanzania. Malar J. 2011;10:80.

14. Etang J, Pennetier C, Piameu M, Bouraima A, Chandre F, Awono-Ambene $P$, et al. When intensity of deltamethrin resistance in Anopheles gambiae s.l. leads to loss of Long lasting insecticidal nets bio-efficacy: a case study in north Cameroon. Parasit Vectors. 2016;9:132.

15. Durnez L, Coosemans M. Residual transmission of malaria: An old Issue for new approaches. In: Manguin S, editor. Anopheles mosquitoes-new insights into malar vectors. Rijeka: Intech Open Science Publ; 2013. p. $671-704$.

16. Dabiré RK, Namountougou M, Diabaté A, Soma DD, Bado J, Toé HK, et al. Distribution and frequency of kdr mutations within Anopheles gambiae s.l. populations and first report of the Ace.1G119S mutation in Anopheles arabiensis from Burkina Faso (West Africa). PLoS ONE. 2015;10:e0141645.

17. Dabiré RK, Namountougou M, Sawadogo SP, Yaro LB, Toé HK, Ouari A, et al. Population dynamics of Anopheles gambiae s.l. in Bobo-Dioulasso city: bionomics, infection rate and susceptibility to insecticides. Parasit Vectors. 2012;5:127.

18. Bamou R, Mbakop LR, Kopya E, Ndo C, Awono-Ambene P, Tchuinkam T, et al. Changes in malaria vector bionomics and transmission patterns in the equatorial forest region of Cameroon between 2000 and 2017. Parasit Vectors. 2018;11:464.

19. Salako AS, Ahogni I, Kpanou C, Sovi A, Azondekon R, Sominahouin AA, et al. Baseline entomologic data on malaria transmission in prelude to an indoor residual spraying intervention in the regions of Alibori and Donga, Northern Benin, West Africa. Malar J. 2018;17:392.

20. Gillies M, Coetzee M. A supplement to the Anophelinae of Africa South of the Sahara (Afrotropical Region). South African Inst Med Res. 1987:55:1-143.

21. Detinova TS. Age-grouping methods in Diptera of medical importance with special reference to some vectors of malaria. Monogr Ser World Health Organ. 1962;47:13-91.

22. Santolamazza F, Mancini E, Simard F, Qi Y, Tu Z, della Torre A. Insertion polymorphisms of SINE200 retrotransposons within speciation islands of Anopheles gambiae molecular forms. Malar J. 2008:7:163.

23. Wirtz RA, Zavala F, Charoenvit Y, Campbell GH, Burkot TR, Schneider I, et al. Comparative testing of monoclonal antibodies against Plasmodium falciparum sporozoïtes for Elisa development. Bull World Health Organ. 1987:65:39-45

24. Beier JC, Perkins PV, Wirtz RA, Koros J, Diggs D, Gargan TP, et al. Bloodmeal identification by direct enzyme-linked immunosorbent assay (ELISA), tested on Anopheles (Diptera: Culicidae) in Kenya. J Med Entomol. 1988;25:9-16.

25. WHO. Test procedures for insecticide resistance monitoring in malaria vectors, Bioefficacy and persistence of insecticides on treated surfaces. Geneva: World Health Organization; 1998.

26. Martinez-Torres DEA. Molecular characterizationof pyrethroid knockdown $(\mathrm{kdr})$ in the major malaria vector Anopheles gambiae s.s. Insect Mol Biol. 1998;7:179-84.

27. Weill M, Malcolm C, Chandre F, Mogensen K, Berthomieu A, Marquine M, et al. The unique mutation in ace-1 giving high insecticide resistance is easily detectable in mosquito vectors. Insect Mol Biol. 2004;13:1-7.

28. The R Development Core Team. R: a language and environment for statistical computing; 2008. p. 1-2547. http://www.gnu.org/copyleft/gpl.html.

29. Magnusson A, Skaug H, Nielsen A, Berg C, Kristensen K, Maechler M, et al. Generalized linear mixed models using template model builder. 2019. p. 1-32. https://github.com/glmmTMB

30. Russell L, Henrik S, Love J, Buerkner P, Herve M. Estimated marginal means, aka least-squares means: package 'emmeans'. BugReports. 2019. p. 216-21. https://www.github.com/rvlenth/emmeans.

31. Raymond M, Rousset F. GENEPOP: population genetics software for exact tests and ecumenicism. J Hered. 1995:86:9-10.

32. Pages F, Orlandi-pradines E, Corbel V. [Vectors of malaria : biology, diversity, prevention, and individual protection](In French). Med Mal Infect. 2007;37:153-61.

33. Soma DD, Zogo BM, Somé A, Tchiekoi BN, de Sales Hien DF, Pooda HS, et al. Anopheles bionomics, insecticide resistance and malaria transmission in southwest Burkina Faso: a pre-intervention study. PLoS ONE. 2020;15:e0236920.

34. Gillies M, Meillon D. The Anophelinae of Africa south of the Sahara (Ethiopian zoogeographical region). Sahara Ethiop Zoogeographical. 1968;343 pp.

35. Guelbeogo WM, Sagnon NF, Grushko O, Yameogo MA, Boccolini D, Besansky NJ, et al. Seasonal distribution of Anopheles funestus chromosomal forms from Burkina Faso. Malar J. 2009;8:239. 
36. Moiroux N, Bio-Bangana AS, Djènontin A, Chandre F, Corbel V, Guis H. Modelling the risk of being bitten by malaria vectors in a vector control area in southern Benin, West Africa. Parasit Vectors. 2013;6:71.

37. Dabiré K, Baldet T, Diabaté A, Dia I, Costantini C, Cohuet A, et al. Anopheles funestus (Diptera: Culicidae) in a humid savannah area of western Burkina Faso: bionomics, insecticide resistance status, and role in malaria transmission. J Med Entomol. 2007;44:990-7.

38. Robert V, Chippaux, Jean-philippe LD. Le paludisme en Afrique de l'Ouest: Etudes entomologiques et épidemiologiques en zone rizicole et en milieu urbain. ORSTOM. 1991.

39. Adja AM, N'Goran KE, Kengne P, Koudou GB, Toure M, Koffi AA, et al. [Transmission vectorielle du paludisme en savane arborée à Gansé en Côte d'Ivoire](in French). Med Trop (Mars). 2006;65:449-55.

40. Akono APN, Tcheugoue GRJ, Mbida JA, Lehman LG. Higher Mosquito aggressiveness and malaria transmission following the distribution of alpha-cypermethrin impregnated mosquito nets in a district of Douala, Cameroon. Afr Entomol. 2018;26:429-36.

41. Sovi A, Azondékon R, Aïkpon RY, Govoétchan R, Tokponnon F, Agossa F, et al. Impact of operational effectiveness of long-lasting insecticidal nets (LLINs) on malaria transmission in pyrethroid-resistant areas. Parasit Vectors. 2013;6:319.

42. Dabiré KR, Diabaté A, Paré-Toé L, Rouamba J, Ouari A, Fontenille D, et al. Year to year and seasonal variations in vector bionomics and malaria transmission in a humid savannah village in west Burkina Faso. J Vector Ecol. 2008;33:70-5

43. Dabiré KR, Diabaté A, Namountougou M, Toé KH, Ouari A, Kengne P, et al. Distribution of pyrethroid and DDT resistance and the L1014F kdr mutation in Anopheles gambiae s.l. from Burkina Faso (West Africa). Trans R Soc Trop Med Hyg. 2009;103:1113-20.

44. Chouaïbou MS, Fodjo BK, Fokou G, Allassane OF, Koudou BG, David J, et al. Influence of the agrochemicals used for rice and vegetable cultivation on insecticide resistance in malaria vectors in southern Côte d'Ivoire. Malar J. 2016;15:426.

45. Hien SA, Soma DD, Hema O, Bayili B, Namountougou M, Gnankiné O, et al. Evidence that agricultural use of pesticides selects pyrethroid resistance within Anopheles gambiae s.I. populations from cotton growing areas in Burkina Faso, West Africa. PLoS ONE. 2017;3:e0173098.

46. WHO. List of WHO Prequalification vector control products. Geneva: World Health Organization; 2019. https://www.who.int/pq-vector-contr ol/prequalified-lists/LOPrequalifiedProducts20190411.pdf?ua=1.

47. Mashauri FM, Manjurano A, Kinung'hi S, Martine J, Lyimo E, Kishamawe C, et al. Indoor residual spraying with microencapsulated pirimiphos-methyl (Actellic $^{\circledR}$ 300CS) against malaria vectors in the Lake Victoria basin, Tanzania. PLoS ONE. 2017;12:e0176982.

48. Sy O, Niang EHA, Ndiaye M, Konaté L, Diallo A, Ba ECC, et al. Entomological impact of indoor residual spraying with pirimiphos-methyl: a pilot study in an area of low malaria transmission in Senegal. Malar J. 2018;17:64

49. Namountougou M, Soma DD, Kientega M, Balboné M, Kaboré DPA, Drabo $\mathrm{SF}$, et al. Insecticide resistance mechanisms in Anopheles gambiae complex populations from Burkina Faso, West Africa. Acta Trop. 2019:197:1-9.

50. Namountougou M, Simard F, Baldet T, Diabate A, Ouedraogo JB, Martin T, et al. Multiple insecticide resistance in Anopheles gambiae s.l. populations from Burkina Faso, West Africa. PLoS ONE. 2012;7:e48412.

\section{Publisher's Note}

Springer Nature remains neutral with regard to jurisdictional claims in published maps and institutional affiliations.
Ready to submit your research? Choose BMC and benefit from:

- fast, convenient online submission

- thorough peer review by experienced researchers in your field

- rapid publication on acceptance

- support for research data, including large and complex data types

- gold Open Access which fosters wider collaboration and increased citations

- maximum visibility for your research: over $100 \mathrm{M}$ website views per year

At BMC, research is always in progress.

Learn more biomedcentral.com/submissions 